\title{
O TRABALHO PEDAGÓGICO CRIATIVO NA EDUCAC̦̃̃O INFANTIL DIANTE DA CULTURA DA MÍDIA E DO CONSUMO
}

\author{
Mariangela Momo* \\ Universidade Federal do Rio Grande do Norte, (UFRN), Natal - RN, Brasil \\ Albertina Mitjáns Martínez"* \\ Universidade de Brasília (UnB), Brasília - DF, Brasil
}

RESUMO: Considerando-se que as crianças contemporâneas vivem uma cultura da mídia e do consumo em diferentes contextos, inclusive no interior das escolas, tomou-se como fundamentação a Epistemologia Qualitativa de González Rey e desenvolveu-se uma pesquisa em quatro escolas públicas no Distrito Federal/Brasil em 2015, para investigar e analisar processos criativos de ensino-aprendizagem diante dessa cultura. Utilizaram-se instrumentos como entrevistas, observações e fotografias, visando produzir informações sobre o trabalho pedagógico criativo. $\mathrm{O}$ arcabouço teórico - advindo, sobretudo, dos estudos sobre a criatividade de Mitjáns Martínez -, articulado com informações construídas nas escolas, representou vias de inteligibilidade da questão investigada. A produção de algo novo e com valor no trabalho pedagógico envolveu: considerar essa cultura em distintas práticas escolares; utilizar estratégias metodológicas relacionadas a ela; e selecionar e desenvolver conteúdos na relação com essa cultura em forma de projetos. Conclui-se que o trabalho pedagógico criativo é uma das vias possíveis e necessárias diante dessa cultura.

Palavras-chave: Cultura da mídia. Cultura do consumo. Educação infantil. Trabalho pedagógico criativo. Criatividade.

\footnotetext{
"Pedagoga, Especialista em Educação Infantil e Doutora em Educação pela Universidade Federal do Rio Grande do Sul (UFRGS). Pós-doutora pelo Programa de Pós-Graduação em Educação da Universidade de Brasília (UNB). Atualmente, é professora Associada do Centro de Educação da Universidade Federal do Rio Grande do Norte (UFRN). E-mail: < marimomo@terra.com.br > .

"Psicóloga, Doutora em Ciências Psicológicas pela Universidade de Havana com estágio pós-doutoral na Universidade Autônoma de Madri. Pesquisadora colaboradora do Programa de Pós-Graduação em Educação da Universidade de Brasília, Líder do Grupo de Pesquisa Aprendizagem, Escolarização e Desenvolvimento Humano cadastrado no CNPq. E-mail: < amitjans49@gmail.com > .
} 


\title{
CREATIVE PEDAGOGICAL WORK IN CHILDREN EDUCATION IN RELATION TO THE MEDIA AND CONSUMER CULTURE
}

\begin{abstract}
The works aims to investigate and analyze the creative teachinglearning processes in a media and consumer culture and its influence on children, even in the public schools. The study have used instruments such as interviews, observations and pictures, conducted in four public schools at Brazilian central region in 2015, to produce information about the creative pedagogical work. The theoretical basis, deriving from studies of creativity by Mitjáns Martínez, among others, articulated with information obtained from the schools, have provided a means to understand the issue under investigation. The production of something new and valuable in the pedagogical work has involved (a) considering this culture in different school practices; (b) using methodological strategies related to it; and (c) selecting and developing projects related to this culture. We have concluded that the creative pedagogical work is one of the possible and necessary in face of this new culture.
\end{abstract}

Keywords: Media culture. Consumer culture. Children Education. Creative pedagogical work. Creativity.

\section{A CULTURA DA MÍDIA E DO CONSUMO E A SUBJETIVIDADE DAS CRIANC̣AS CONTEMPORÂNEAS}

Há evidências, em diferentes campos da atuação humana - como as invenções na área das tecnologias da comunicação, da informação e do próprio transporte -, sobre significativas alterações nas faces do mundo a partir da segunda metade do século XX. Essas evidências têm sido estudadas, descritas, interpretadas e problematizadas por um conjunto de autores, entre os quais, Bauman (1999a, 1999b, 2001, 2008), Harvey (1993), Jameson (2004) e Debord (1997), que se empenham em compreender este surpreendente mundo novo. $\mathrm{Na}$ busca por essa compreensão, esses autores criam, inclusive, novas formas de nomear o nosso tempo e o nosso mundo, a saber: modernidade líquida, pós-moderno e sociedade do espetáculo.

Esses estudos, em conjunto com outros, como os de Kellner (1995, 2001), Lipovetsky (2004) e Canclini (2003), consideram as variadas transformações que aconteceram no mundo pós-Segunda Guerra Mundial. Entre essas transformações, estão as modificações nas relações espaço-temporais - é possível acessar vários espaços (como os virtuais) em tempo nenhum, diferentemente da época das grandes navegações, quando, para se acessar ou dominar um espaço, geralmente eram necessários muitos dias ou até meses; a globalização 
de mercadorias, imagens, valores e modos de vida (CANCLINI, 2003); a efemeridade de bens materiais e das próprias relações humanas; o excesso de objetos e a produção de grande quantidade de lixo, incomparável com a de qualquer outra época na história da humanidade (basta pensar aqui na descartabilidade dos aparelhos celulares, por exemplo); e a comercialização de bens imateriais, como marcas/logos e serviços (como os atrelados à telefonia móvel). No contexto dessas transformações, ocorreram e têm ocorrido profundas alterações, nunca antes vistas, no âmbito da cultura.

Em seu livro intitulado Cultura e Sociedade, Reymond Williams (1969) expôs mais de 200 formas de definir o termo cultura. Esse é um bom exemplo de que não há uma definição unívoca ou verdadeira para esse conceito, mas diferentes formas de compreendê-lo e de operar com ele, de acordo com distintas perspectivas teóricas. Por isso, neste artigo, expomos alguns de nossos entendimentos sobre a cultura da mídia e do consumo, considerando as transformações ocorridas no mundo nas últimas décadas. Essa opção foi feita por considerarmos que as crianças que nascem neste início do século XXI - pelo menos as que nascem e vivem nos grandes centros urbanos - estão se constituindo como seres humanos no interior dessa cultura. Para expor a compreensão do que entendemos por cultura da mídia e do consumo, lançamos mão de um conjunto de estudos provenientes de diferentes campos do conhecimento, como as Ciências Sociais e os Estudos Culturais.

Uma das significativas alterações no mundo contemporâneo em relação à cultura refere-se ao fato de que cada vez mais ela deixa de ser produzida e propagada segundo costumes locais e em âmbito local e passa a ser produzida e propagada em escala global por grandes corporações empresariais, que movem as engrenagens do complexo sistema capitalista ao promoverem o consumo por meio da mídia. Essa afirmação está baseada no entendimento de que a cultura, como sintetiza Hall (2004), tem a ver com significados partilhados. Nas práticas de utilização da linguagem, significados são produzidos e compartilhados, ensinados e aprendidos, configurando determinadas culturas (MOREIRA; CANDAU, 2007). Desse modo, a partir de um conjunto de invenções midiáticas, tanto no que se refere a aparatos de difusão da informação (televisão, revistas, rádio, cinema, computador, internet, sistemas telefônicos, etc.) quanto no que tange aos artefatos que esses aparatos colocam em circulação (noticiários, filmes, desenhos animados, programas musicais, culinários e esportivos, jogos, personagens, peças publicitárias, etc.), utiliza-se uma linguagem cada vez mais visual. Tal linguagem pode ser 
facilmente entendida por grande parte das pessoas em qualquer parte do globo, incluindo crianças muito pequenas, o que configura uma cultura global, uma cultura da mídia e do consumo.

A mídia tem alterado os processos de produção, circulação e consumo de significados. Em outras palavras, a mídia, por meio de uma linguagem específica, tem colocado em circulação um conjunto de significados que acaba configurando uma cultura comum, uma cultura da mídia (KELLNER, 1995, 2001) e do consumo (BAUMAN, 1999a, 1999b, 2001, 2008). Trata-se de uma cultura produtiva no âmbito da significação e da organização dos modos de vida e na proliferação de determinados valores.

Segundo Kellner (2001), as imagens e as narrativas produzidas e propagadas pela mídia, amplamente reconhecidas e compartilhadas, possibilitam a formação de uma cultura comum, uma cultura da mídia e, imbricada nesta, pode-se dizer, uma cultura do consumo. Isso acaba ajudando a tecer a vida cotidiana de muitas pessoas, modelando opiniões, formas de pensar e parâmetros sobre valores, modos de ser e de agir em diferentes pontos do globo. Dito de outro modo, muitos dos significados culturais são postos em circulação por meio da mídia, configurando o que poderíamos chamar de uma cultura da mídia e do consumo.

Trata-se de uma cultura amplamente aceita e (re)produzida pelas pessoas em muitos aspectos de suas vidas cotidianas, ainda que por meio dos assuntos sobre os quais falam. Segundo Lipovetsky (2004), essa cultura seria uma das responsáveis por promover novas formas de sociabilidade. Para o autor, as formas tradicionais de vida comunitária estariam se rompendo (na noite de Natal, não se vai mais à missa, diz o autor, liga-se a televisão) e sendo substituídas por formas de sociabilidade atreladas à cultura da mídia. Um exemplo disso seria a participação em emoções, em escala global, promovidas pela mídia, como a Copa do Mundo de Futebol.

Em relação ao consumo, ele pode ser entendido não apenas como o consumo de bens materiais, mas também como o consumo de significados, modos de vida, formas de representação e valores. Bauman $(2001,2008)$ argumenta que estamos vivendo em uma sociedade na qual as pessoas são valorizadas e posicionadas segundo a sua capacidade de consumo, diferentemente da sociedade que a precedeu, que seria uma sociedade da produção, onde as pessoas eram valorizadas e posicionadas de acordo com a sua capacidade de produção. A argumentação do autor não significa que não existam mais lógicas organizativas que se assentam sobre a esfera da produção, mas que a maioria das lógicas está 
permeada pela esfera do consumo. Isso dá indicativos de que, para que essas lógicas existam, é imprescindível que haja uma cultura comum, no sentido de significados amplamente compartilhados, uma cultura do consumo, uma cultura que é produzida por meio da mídia, imprimindo determinadas normas, regras e valores. Em relação à função normativa da mídia, Lipovetsky (2004) diz que a mídia impõe determinados modelos (do que se deve consumir, por exemplo) de forma não obrigatória e, mesmo assim, tem efeitos eficazes. Costa e Silveira (1998, p. 350) também argumentam que "[...] a ação da mídia sobre nós não se reveste de nenhuma forma de violência; pelo contrário, ela é geralmente prazerosa, contando com a nossa adesão [...]".

Ao mesmo tempo, não estamos considerando que todas as pessoas sujeitas a condições culturais semelhantes, como a cultura da mídia e do consumo, sejam seres passivos e reprodutores dessa cultura. Pelo contrário, ao considerarmos a Teoria da Subjetividade de González Rey (2004, 2011b, 2011c, 2012), entendemos que as pessoas são seres (inter)ativos que, mesmo participando de condições culturais semelhantes, podem, na condição de sujeitos, gerar sentidos subjetivos que fogem aos sentidos hegemônicos expressos na cultura da mídia e também do consumo.

Por outro lado, questionamo-nos em que medida as crianças contemporâneas, ao produzirem sentidos, têm fugido ou não aos sentidos hegemônicos que circulam na cultura da mídia e do consumo. Quanto à cultura infantil, Steinberg e Kincheloe (2001) apontam que uma das principais mudanças em relação a outras épocas está no fato de que ela deixou majoritariamente de ser produzida, inventada e propagada pelas crianças segundo costumes locais, passando a ser produzida por adultos em grandes corporações que visam ao lucro. Dessa perspectiva, podemos entender a criação e a propagação de ícones (como o Homem Aranha, por exemplo) por meio de significados que são compartilhados nos mais diversos contextos e que até há pouco tempo não existiam. Esses ícones (bem como muitas marcas e logos), mediante a cultura da mídia e do consumo, passam a fazer parte da vida das crianças e de muitas práticas culturais que as envolvem (como festas de aniversário, materiais escolares e uma infinidade de produtos direcionados ao público infantil, entre eles, jogos e brinquedos). Assim, configura-se uma determinada cultura infantil, que é também uma cultura da mídia e do consumo.

Em seu livro intitulado Nascidos para Comprar, Shor (2009) evidenciou como grandes corporações empresariais empreendem esforços para a criação tanto de produtos quanto de estratégias de 
divulgação desses produtos, esforços que dependem de um grande investimento financeiro e que congregam especialistas de várias áreas do conhecimento que, juntos, desenvolvem tanto produtos quanto estratégias que poderíamos interpretar como criativas. Citamos brevemente dois exemplos estudados pela autora. Um deles é a contratação, por uma determinada empresa de produtos de higiene para crianças, de especialistas de diferentes áreas, como pedagogos, psicólogos, psicomotricistas e fonoaudiólogos, para observar momentos do banho e troca de fraldas de alguns bebês em seus contextos familiares. Para permitir a realização dessas observações, as famílias geralmente recebem algum dinheiro. Após o estudo dessas observações, passam a compor a equipe profissionais de outras áreas, como do design, da informática e da publicidade, e criam-se tanto um novo produto quanto estratégias midiáticas para sua divulgação (basta pensar aqui, por exemplo, em xampus com determinadas fragrâncias acondicionados em frascos em formatos de carrinhos, bonecas e bichinhos que até recentemente não existiam). Outro exemplo é a criação de novos jogos de videogame, também desenvolvidos por uma equipe multidisciplinar de especialistas de uma determinada empresa de jogos eletrônicos e a utilização de uma estratégia de marketing nomeada como "viral". Trata-se da identificação de crianças ciber (crianças que têm acesso à internet e que a utilizam com frequência, fazendo parte de redes sociais e vivendo em diferentes países) e da distribuição gratuita desses jogos para essas crianças com o único compromisso de que, se elas gostarem de um jogo, deverão divulgá-lo para o maior número de amigos possível. Com essa estratégia, associada também a outras, o jogo vai se tornando conhecido por meio da "contaminação": uma criança vai contaminando outra, que vai contaminando outra e mais outra, até que o jogo se torne conhecido em escala global.

Desses dois exemplos, pode-se depreender que as criações realizadas são frutos de grandes investimentos intelectuais e financeiros, comprometidos unicamente com a lucratividade e regidos pela oferta de prazer. Nesse sentido, destacamos que a criatividade não está atrelada, necessariamente, à ética (neste caso, em relação às crianças), mas está muito mais relacionada ao contexto social e cultural de cada época e lugar. Inclusive, a compreensão do conceito de criatividade não como uma capacidade psicológica inata ao indivíduo, mas como um processo humano constituído nas condições concretas das sociedades e de seus contextos sociorrelacionais específicos (MITJÁNS MARTÍNEZ, 2004), remete 
à indissociabilidade entre criatividade e contexto sociocultural em que os indivíduos estão inseridos. Vigostsky (2009) argumentava que todo inventor é sempre fruto do seu tempo e do seu meio e que as invenções só são possíveis após a criação de determinadas condições materiais e psicológicas para o seu desenvolvimento.

A partir de uma perspectiva histórico-cultural, Mitjáns Martínez (1997, 2004, 2009, 2014b) compreende a criatividade como um processo complexo da subjetividade humana, "[...] na sua simultânea condição de subjetividade individual e subjetividade social que se expressa na produção de 'algo' considerado, ao mesmo tempo, 'novo' e valioso em determinado campo da ação humana [...]" (MITJÁNS MARTÍNEZ, 2014b. p. 70). Para a autora, a criatividade pode expressar-se, no mínimo, de três formas. A primeira delas é como produção de novidade. Nessa perspectiva, a atividade criadora distancia-se da própria ideia de reprodução e não está atrelada a um resultado final, a um produto, mas considera os processos. A segunda, é como capacidade especificamente humana de gerar produtos culturais significativos. Nesse sentido, pode-se interpretar que a significação está intimamente relacionada ao contexto social em que a criação se efetiva. Ao mesmo tempo, a significação pode ser algo atribuído não apenas pelos outros, mas pelo próprio indivíduo responsável pela criação e pelo valor que o produto significa para si próprio (MITJÁNS MARTÍNEZ, 2009). A terceira forma é como capacidade de produção de novidade e valor na vida cotidiana.

No âmbito da pesquisa realizada, considerando a proeminência da cultura da mídia e do consumo na vida das crianças, pelo menos das que habitam os grandes centros urbanos, tomamos a criatividade como expressão da subjetividade das crianças como um dos focos de interesse. O entendimento da criatividade como expressão da subjetividade advém dos estudos sobre a criatividade de Mitjáns Martínez (1997, 2004, 2009) e de suas aproximações com os estudos sobre a Teoria da Subjetividade de González Rey (2004, 2011b, 2011c, 2012).

Consideramos criações que se configuram como novidade para o contexto escolar - vividas em processos de brincadeiras (como ser o Homem Aranha), em construções coletivas de narrativas (como criação de história com elementos do filme Frozenn), em construções de materialidades (como esculturas de massinha de modelar de dinossauros), em desenhos (do Ben 10) e em composições por meio de recortes e colagens (pistas do Hot Wheels), entre outras vivências. Tais criações estabelecem relação com a cultura da mídia e do consumo, sendo rapidamente reconhecidas e amplamente compartilhadas 
pelas outras crianças. Assim, essas criações caracterizam-se como culturalmente significativas e de valor para as próprias crianças na vida cotidiana dos contextos escolares e, na maioria das muitas situações, fogem ao que está sendo proposto pelas professoras. Em outras palavras, constatamos que grande parte das produções simbólicoemocionais de muitas crianças - sua subjetividade - se constitui na relação com a cultura da mídia e do consumo.

Podemos afirmar que, diante das crianças contemporâneas - que são constituídas pela cultura da mídia e do consumo e que a constituem -, grande parte das professoras se sente inquieta, não sabe muito bem como agir e o que fazer no cotidiano de suas salas de aula. A escola em vigor parece já não dar conta das novas crianças que a habitam. Mariangela Momo, coautora deste texto, movida por inquietações em relação à(s) infância(s) contemporânea(s), tem desenvolvido estudos e pesquisas para compreender as crianças que estão em escolas de Educação Infantil no início deste século XXI. Seus estudos apontam que efemeridade, flexibilidade, imediatismo, descartabilidade e visibilidade fazem parte da vida dessas crianças, caracterizando o surpreendente mundo novo. A aproximação dos estudos desta com os estudos de Albetina Mitjáns Martínez, outra coautora deste texto, que há mais de 20 anos pesquisa o tema da criatividade, permitiu perceber que a criatividade poderia ser uma importante alternativa para o trabalho pedagógico em turmas da Educação Infantil. O objetivo seria favorecer a aprendizagem e o desenvolvimento das crianças, bem como minimizar determinados efeitos que tal cultura poderia ter em muitas delas.

Assim, durante o ano de 2015 (de abril a outubro), em um trabalho de parceria, tomamos como fundamentação a Epistemologia Qualitativa de González Rey (1997, 2002, 2011a, 2014) e desenvolvemos uma metodologia qualitativa de investigação em quatro escolas públicas que tinham turmas de Educação Infantil no Distrito Federal - uma escola localizada no Plano Piloto de Brasília e as outras três em três distintas cidades-satélites. Uma escola atendia apenas à Educação Infantil, duas tinham Educação Infantil e os anos Iniciais do Ensino Fundamental, e a outra oferecia Educação Infantil e o Ensino Fundamental completo. Em todas as escolas, a maior parte dos alunos era caracterizada por baixa renda, mas na escola do Plano Piloto de Brasília a renda das famílias dos alunos era maior quando comparada às das outras escolas da pesquisa. Em cada uma das escolas, selecionamos uma professora, elegendo como critério o reconhecimento por parte da escola de que era uma 
professora criativa ${ }^{1}$, e sua turma de alunos, com quatro ou cinco anos de idade. Partindo do entendimento de que o pesquisador passa a ser o produtor de construções-interpretações " [...] dentro dos complexos sistemas de informação, nos quais vão surgindo aspectos relevantes do problema estudado" (GONZÁLEZ REY, 2002, p. 13), utilizamos, para a pesquisa nas turmas, mas também nas escolas como um todo, um conjunto de instrumentos, entre os quais, entrevistas, observações, fotografias, e análise documental. O objetivo era produzir informações sobre aspectos do trabalho pedagógico criativo (das professoras) diante da cultura da mídia e do consumo. As observações de aulas, reuniões, festividades e passeios foram efetivadas com o intuito de selecionar e registrar - em diário de campo, filmagens e fotografias - situações que tivessem relação com a cultura da mídia e do consumo e com o trabalho pedagógico criativo diante dessa cultura. A periodicidade das observações realizadas em cada escola durante todo o tempo da pesquisa variou majoritariamente entre semanal e quinzenal, em virtude de ajustes com a agenda letiva das escolas, entre os meses de abril e outubro de 2015. Os documentos selecionados foram as atividades realizadas e registradas pelas crianças, os materiais produzidos pela professora, tais como cartazes e histórias, o projeto político-pedagógico de cada escola e a Lei $\mathrm{N}^{0} 5.146^{2}$ (BRASIL, 2013). A seleção das informações presentes em cada documento também considerou como principal critério relações com a cultura da mídia e do consumo e com o trabalho pedagógico criativo na relação com essa cultura. As entrevistas foram realizadas com as professoras e as coordenadoras pedagógicas de cada escola e tiveram a intenção de esclarecer e ampliar informações que já vinham sendo construídas por meio dos outros instrumentos sobre o objeto de estudo. Neste artigo, valemo-nos de um conjunto de informações que visam evidenciar o trabalho pedagógico criativo na Educação Infantil diante da cultura da mídia e do consumo. Não temos a pretensão de abranger o total das informações produzidas em cada escola e consideramos três das quatro escolas pesquisadas por ser nestas que o trabalho pedagógico criativo se estabeleceu com maior ênfase na relação com a cultura da mídia e do consumo.

$\mathrm{O}$ arcabouço teórico foi tomado como um sistema de conceitos - advindos dos estudos sobre a criatividade de Mitjáns Martínez (1997, 2004, 2008, 2009, 2014a, 2014b, 2014c), por ser, entre os autores que trabalham a criatividade na escola, quem tem estudado e definido de forma específica a criatividade no trabalho pedagógico; da Teoria da Subjetividade de González Rey (2004, 2011b, 2011c, 2012), 
por considerarmos a criatividade como expressão da subjetividade (individual e social); e de estudos sobre a cultura da mídia e do consumo, tais como os de Kellner $(1995,2001)$ e de Bauman (1999a, 1999b, 2001, 2008), que nos ajudam a compreender a cultura na qual as crianças contemporâneas estão imersas. Articulados com as informações construídas nas escolas, esses conceitos representaram vias de inteligibilidade sobre a criatividade no trabalho pedagógico das professoras diante da cultura da mídia e do consumo.

Sublinhamos que foram muitos os acontecimentos, as vivências e as situações presenciadas no contexto de cada escola investigada. No entanto, circunscrevemos os registros ao objetivo da pesquisa e realizamos o processo construtivo interpretativo, considerando o trabalho das professoras nas suas relações com a cultura da mídia e do consumo. Isso, certamente, não representa a totalidade do trabalho por elas realizado, nem mesmo a qualidade do seu trabalho em outros aspectos aqui não abordados.

\section{O TRABALHO PEDAGÓGICO DAS PROFESSORAS EM TURMAS DA EDUCAC̣ÃO INFANTIL DIANTE DA CULTURA DA MÍDIA E DO CONSUMO: ASPECTOS CRIATIVOS}

A expressão da criatividade no trabalho pedagógico é um tema de estudo de longa data de Mitjáns Martínez (2014b, p. 70), que a entende como "[...] formas de realização deste que representa algum tipo de novidade e que resultam valiosas de alguma forma para a aprendizagem e o desenvolvimento dos alunos". Visando contribuir com a aprendizagem e o desenvolvimento dos alunos por meio de um trabalho pedagógico criativo, Mitjáns Martínez (1997) formulou o que denominou de Sistema Didático Integral. Esse sistema compreende apontamentos sobre a necessidade de novas formas de realizar o trabalho pedagógico que significam possibilidades de criatividade em diferentes aspectos, como: na formulação e na seleção dos objetivos de aprendizagem; na seleção e na organização dos conteúdos de ensino; na flexibilidade e na dialogicidade das estratégias e dos métodos de ensino; na seleção e na organização da bibliografia e do material didático; na realização de avaliações e autoavaliações; nas relações professor-aluno; e no clima comunicativo emocional da sala de aula e da própria escola. Isso evidencia que a criatividade no trabalho pedagógico pode existir em qualquer um dos elementos constitutivos desse trabalho e não, necessariamente, em todos os elementos ao mesmo tempo, embora, para compor o Sistema Didático Integral, deva existir em todos os elementos desse sistema. Além disso, Mitjáns Martínez (1997) considera 
que a criatividade se apresenta em diferentes níveis, que podem variar de um nível máximo, do qual são representantes cientistas, artistas e inventores muito relevantes, até um nível primário, representado, por exemplo, por algumas condutas das crianças.

Diferentemente das grandes corporações empresariais, que dispõem de equipes multidisciplinares e de distintos e variados recursos e que investem milhões em processos criativos para atingir o público infantil na busca por torná-lo consumidor, as professoras das escolas públicas estudadas não dispõem dessas possibilidades. Ainda assim, desenvolvem estratégias, ações e pequenos projetos criativos, diante da cultura da mídia e do consumo, visando também, embora com outros objetivos, "atingir" as crianças que estão cotidianamente em suas salas de aula e colaborando em seus processos de aprendizagem e desenvolvimento. Desse modo, apesar de reconhecermos que o trabalho pedagógico criativo deva considerar todos os elementos do Sistema Didático Integral, no caso das professoras estudadas, apreciamos a criatividade em alguns desses elementos. Ao mesmo tempo, consideramos que da criatividade no trabalho pedagógico participam "[...] tanto as configurações subjetivas do professor e sua condição de sujeito, quanto as configurações subjetivas do espaço escolar e de outros espaços sociais vinculados com ele" (MITJÁNS MARTÍNEZ, 2014b, p. 76). Também ponderamos que as configurações subjetivas das crianças como constituintes da subjetividade social da escola participam, em muitos momentos, de aspectos do trabalho pedagógico criativo.

Em relação às ações criativas no trabalho pedagógico das professoras diante da cultura da mídia e do consumo, elas se caracterizaram por formas singulares, complexas e personalizadas, algumas das quais apresentamos neste artigo. A produção de algo novo e com valor no seu trabalho pedagógico e sua expressão na aprendizagem e no desenvolvimento das crianças e na escola teve certos aspectos semelhantes.

Um dos aspectos comuns a todas as professoras é que elas procuravam participar, de algum modo, da cultura infantil e de determinadas práticas vividas cotidianamente por seus alunos e alunas. Essa busca por fazer parte da cultura compartilhada pelas crianças envolvia vários aspectos e era distinta em cada professora - por exemplo, uma das professoras, ao ir ao parque da escola com as crianças, ficava de pés descalços junto com elas todos os dias, e, frequentemente, tanto as crianças quanto ela ficavam descalças também na sala de aula, uma sala pequena e bastante quente; outra 
professora, ao levar seus alunos junto com um grupo de oito professoras e suas respectivas turmas para um dia de passeio nas piscinas de uma determinada associação, foi uma das poucas que entraram na água e brincaram com as crianças. Porém, a tentativa de participar da cultura infantil estava relacionada, principalmente, a muitas situações que envolviam a cultura da mídia e do consumo, algumas das quais distintas em cada professora e outras semelhantes, por exemplo: quando procuravam saber e conversar sobre os personagens midiáticos que as crianças representavam em suas produções (desenhos, esculturas em massinha de modelar, montagens em peças de lego); quando interagiam com as crianças na sala de informática, buscando compartilhar os jogos eletrônicos que interessavam às crianças; quando, em muitas situações, as crianças falavam de personagens televisivos, desenhos infantis, músicas, jogos e brinquedos vinculados à cultura da mídia e do consumo, e as professoras procuravam entender o que as crianças estavam falando; em situações em que, para obter a atenção das crianças, duas das professoras as chamavam pelo nome de ícones infantis, como Princesas e Power Rangers; ou como no caso de uma das professoras, que, no dia designado pela escola para ser o dia do brinquedo (dia em que as crianças podiam levar brinquedos para a escola), brincava com as crianças e, ao identificar os brinquedos que as interessavam, ela os comprava (como a boneca Polly e seus acessórios) e levava para a escola para socializar com todo o grupo, já que muitas crianças, por falta de condições econômicas, muitas vezes não levavam brinquedos para a escola.

Esses aspectos das práticas das professoras podem ser considerados novos, em alguma proporção, uma vez que usualmente as práticas escolares desconsideram a existência dessa cultura no interior das escolas, seja porque não a percebem, seja porque simplesmente a proíbem. A proibição a essa cultura, ao invés de encontrar formas de lidar com ela, geralmente configura-se por ações nada criativas (embora até possam existir proibições bem criativas). Do modo como estamos entendendo a criatividade - como expressão da subjetividade -, isso acaba por não contribuir com o processo de desenvolvimento dos sujeitos que estão na escola (alunos, professores, familiares, gestores, funcionários). Trata-se aqui do desenvolvimento em vários sentidos, mas poderíamos pensar sobre o tipo de sujeito e de sociedade que se quer formar, uma vez que esses indivíduos estão imersos em uma cultura da mídia e do consumo e, em muitas situações, levam essa cultura para o interior das escolas. Com isso, não 
estamos nos posicionando a favor da reprodução dessa cultura nas escolas, mas apontando que a simples proibição pode não contribuir para o desenvolvimento dos indivíduos e da própria sociedade em relação a essa cultura. Ao mesmo tempo, concordamos que, em muitas situações, a proibição se faz necessária, de acordo com a singularidade de cada contexto.

O que destacamos é que um dos aspectos que marcam o caráter de novidade no trabalho dessas professoras está justamente em considerar, de algum modo e em alguns momentos, essa cultura no trabalho por elas realizado visando à aprendizagem e ao desenvolvimento de seus alunos. Ao considerar, de alguma forma, essa cultura infantil (da mídia e do consumo), as professoras acabam por gerar espaços afetivos relacionais de proximidade e identidade com as crianças, o que favorece a influência educativa. Fazemos essa afirmação ao considerar que qualquer influência educativa real passa pelos sentidos subjetivos gerados pelo aprendiz na sua relação com o outro (GONZÁLEZ REY, 2011c).

Usualmente, as práticas escolares e a cultura escolar são regidas pela ordem, pela durabilidade, pela permanência, pela espera, pela renúncia, pela abnegação. Já a cultura da mídia e do consumo, vivida pelas crianças no interior das escolas, caracteriza-se por efemeridade (por exemplo, dos próprios ícones dos quais falam, das músicas que cantam, das brincadeiras vinculadas à cultura da mídia), simultaneidade (por exemplo, muitos ícones ao mesmo tempo), imediatez (tudo é muito rápido e praticamente não se precisa esperar) e constante busca de prazer. Desse modo, é tarefa bastante difícil para as professoras encontrar formas de não desconsiderar essa cultura, marcadamente presente na vida das crianças que são seus alunos e alunas e distinta da própria cultura escolar. Ainda assim, essas professoras buscam encontrar essas formas, desenvolvendo algumas estratégias criativas, algo novo e com valor no contexto escolar.

Foi o caso de uma das professoras, que, diante da constante presença de moedas em sala de aula, levadas pelas crianças para comprar picolés na escola, decidiu trabalhar os valores e as quantidades de moedas necessárias para a aquisição dos picolés, que custavam $\mathrm{R} \$ 0,50$ e $\mathrm{R} \$ 1,00$. A professora explorou com as crianças o valor das moedas de $\mathrm{R} \$ 0,05$ até $\mathrm{R} \$ 1,00$ utilizando estratégias verbais e visuais e organizou cartazes, conforme as Figuras 1 e 2. Após a elaboração dos cartazes, toda vez que uma criança levava moedas para comprar picolé, a professora ia com ela até os cartazes e realizava exercícios de comparação e quantificação, considerando 
o que estava no cartaz e as moedas que a criança possuía. Fazia isso até que a criança entendesse se seria possível ou não comprar o picolé. Em alguns casos, a quantidade que a criança possuía não era suficiente para realizar a compra, e as próprias crianças, a partir dos exercícios realizados, se davam conta disso. Em outros casos, as crianças não chegavam a essa conclusão, então, a professora explicava e dizia que consumir picolé não era tão saudável quanto consumir o lanche da escola. A professora sempre oferecia o lanche gratuito da escola para todas as crianças, incentivava o consumo desse lanche e também o consumia. A professora deixou claro que procedia assim com as crianças cujas famílias haviam autorizado a compra de picolé. Como os picolés eram vendidos pela escola, essa foi a maneira que ela encontrou de tratar a situação com suas crianças. No mês de julho de 2015, a professora retirou os cartazes da sala e informou que um dos pais, de outra turma, tinha denunciado a venda de picolés pela escola, dizendo que estava tendo muitos problemas com o filho. Por esse motivo, os picolés não estavam mais à venda.

FIGURA 1 - Picolé R\$ 1,00

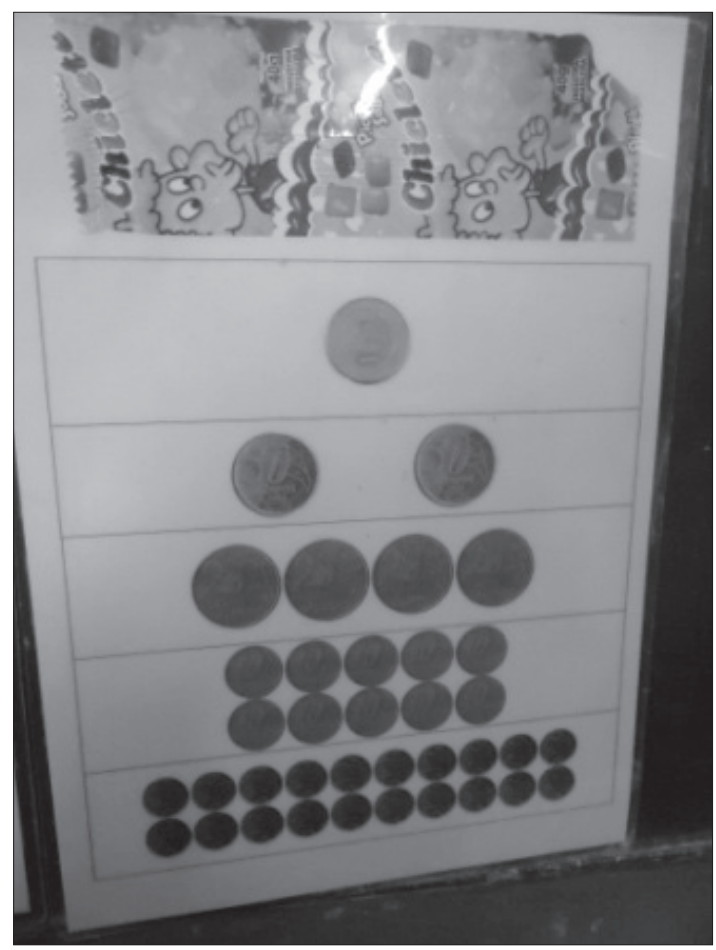

Fonte: Produção das autoras. 
FIGURA 2 - Picolé $\mathrm{R} \$ 0,50$

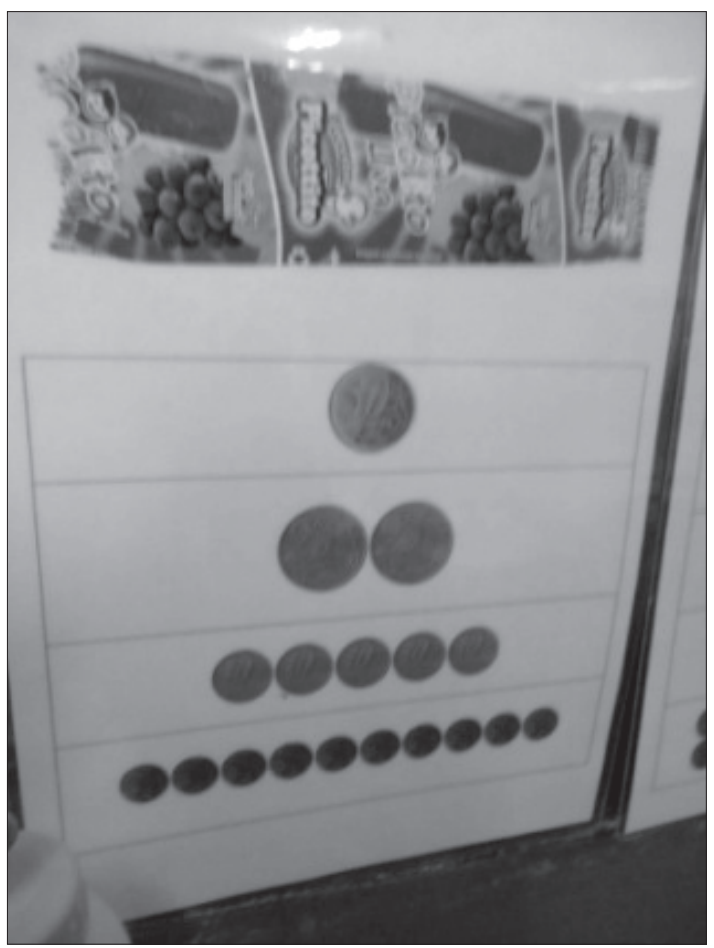

Fonte: Produção das autoras.

Em relação à denúncia realizada pelo pai, ela foi baseada na existência de uma lei ${ }^{3}$ que a professora e alguns outros membros da escola, como o monitor da própria turma, desconheciam. Alguns membros da escola esclareceram que a venda de picolés era realizada para angariar fundos para a escola, dada a insuficiência de recursos fornecidos pelo poder público. Nesse caso, para este artigo, não vamos colocar em debate o fato de a escola vender ou não vender picolés. O que nos interessa é dar visibilidade à estratégia inventada pela professora para lidar com o fenômeno do consumo presente em sua sala de aula, neste caso, utilizando-o para a aprendizagem da matemática. Embora a professora até tenha, no nosso entendimento, colaborado para reproduzir a cultura do consumo, ela criou estratégias novas e com valor no cotidiano de sua sala de aula e da escola. Tais estratégias permitiram determinadas aprendizagens para as crianças e também a formação de determinados valores, entre os quais, o consumo de alimentos saudáveis - no caso, o lanche da escola. Poderíamos dizer que houve criatividade em algum nível nessas estratégias - lembrando que, para Mitjáns Martínez (1997), pode 
haver vários níveis de criatividade. As estratégias foram utilizadas para lidar com algo que até então era problemático e incômodo tanto para a professora (a presença constante de moedas na sala de aula desviava a atenção das crianças), quanto para as crianças, que se interessavam mais pelas moedas e pelos picolés do que pelas atividades de aula.

No ano anterior, essa mesma professora havia desenvolvido um projeto intitulado Crianças livres de pressão consumista e da exposição precoce aos meios de comunicação. A proposta de trabalhar com esse tema chegou para a escola por parte da Secretaria de Educação do Distrito Federal e era um dos temas da Plenarinha ${ }^{4}$ do ano de 2014. No entanto, quando a escola dessa professora recebeu, por parte da Regional de Ensino, o tema a ser trabalhado, nenhuma outra professora se dispôs a desenvolvê-lo com as crianças. Essa professora, mesmo se dispondo a trabalhar, declarou que, inicialmente, não via muito a relação desse tema com a vida das crianças. Foi a partir do filme Criança, a Alma do Negócio, pesquisado e localizado por ela na Internet, que ela passou a ter outra compreensão sobre o tema, distinta da compreensão inicial que tinha. A partir daí, foi criando e proporcionando um conjunto de situações, vivências e atividades que tinham como principais objetivos conhecer a relação das crianças com a cultura da mídia e do consumo e problematizar essa cultura. Assim, iniciou o projeto com atividades lúdicas a partir da música intitulada Videotinha, de Bia Bedran, como cantar, dançar, interpretar a letra da música, dramatizar e criar, com materiais reciclados, uma Videotinha. Uma das estratégias utilizadas foi possibilitar que as crianças fizessem desenhos sobre o que gostavam de ver na televisão. A partir da análise dos desenhos e de outras informações, a professora, em conjunto com as crianças, montou gráficos sobre os programas que as crianças mais gostavam de ver na televisão. Explorou esses gráficos com as crianças, realizando atividades orais de quantificação e de comparação entre as quantidades, assim colaborando para a aprendizagem de conhecimentos matemáticos. Durante essas atividades, a professora foi percebendo que a relação da cultura da mídia com a cultura do consumo era mesmo muito presente nas expressões verbais das crianças e em suas representações gráficas. Ela propôs, então, uma atividade na qual as crianças deveriam não somente desenhar o que mais gostavam de ver na televisão, mas também narrar o que gostavam. As Figuras 3 e 4 são representativas das narrativas das crianças registradas pela professora por ocasião do trabalho por ela desenvolvido. 
FIGURA 3 - Eu vejo Barbie, Monster High...

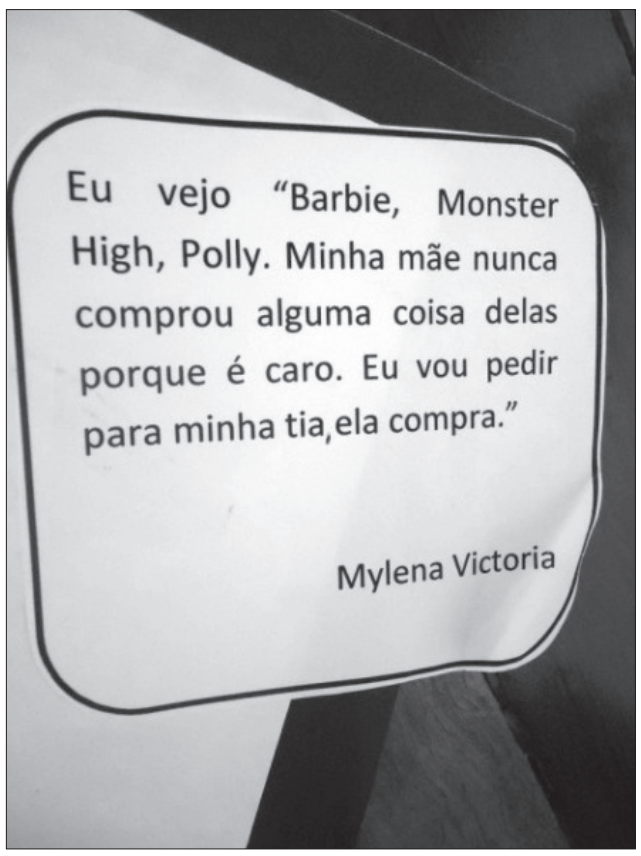

Fonte: Produção das autoras.

Figura 4 - Minha mãe falou que ia comprar...

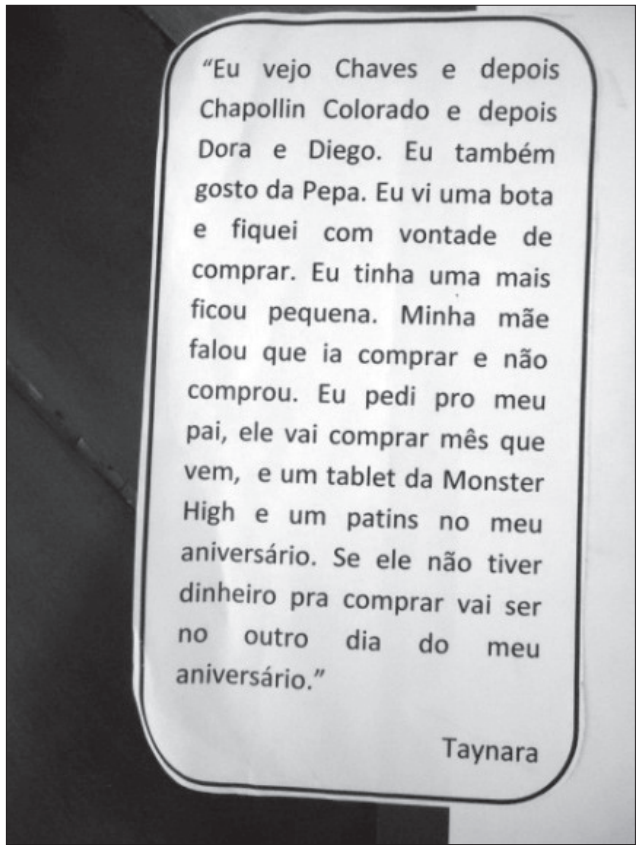

Fonte: Produção das autoras. 
Essas narrativas remetem-nos ao universo dessas crianças, que se mostram significativamente imbricadas na cultura da mídia e do consumo. Elas se mostram conhecedoras de uma variedade de programas televisivos e ícones infantis reconhecidos globalmente, ainda que com impedimentos financeiros para a participação no consumo de bens materiais atrelados a essa cultura: "Minha mãe nunca comprou alguma coisa delas porque é caro. Eu vou pedir para a minha tia, ela compra".

Após a sistematização das narrativas das crianças, a professora decidiu trabalhar de modo mais direto com as questões do consumo, problematizando-o junto com elas. Como não havia materiais sobre o tema na escola, para abordá-lo com as crianças, a professora precisou inventar uma história com imagens que ela capturou na internet. Aliás, a criação no trabalho pedagógico, no âmbito desse projeto, se fez muito presente na própria criação de materiais (pela professora e também pelas crianças) para trabalhar o tema da mídia e do consumo, já que são poucos os materiais disponíveis sobre esses temas que chegam até as escolas. Primeiro, a professora contou a história com uso de datashow; depois, transformou a história em livro; em seguida, após um trabalho de problematização, propôs que cada criança recontasse a história a partir das imagens fornecidas por ela. Depois disso, elaborou uma atividade que os pais deveriam responder e que tinha como objetivo discutir com as crianças as questões do consumo. Nessa atividade, os pais deveriam marcar qual produto comprariam para seus filhos e escrever por quê. Constavam, por exemplo, imagens de mochilas funcionais e com valor financeiro razoável e mochilas com ícones da mídia televisiva, muito mais caras se comparadas com as primeiras. Ainda sobre a busca de parceria com as famílias no trabalho que estava sendo realizado no projeto, a professora propôs outra atividade: as famílias deveriam desligar a televisão durante uma hora e realizar alguma atividade junto com as crianças durante esse tempo em suas casas. No dia seguinte, as crianças contaram na escola o que tinham feito durante o tempo em que a televisão havia ficado desligada.

Poderíamos dar continuidade aqui a um conjunto de vivências e experiências relacionadas ao projeto desenvolvido por esta professora. Porém, mais do que dar visibilidade às atividades desenvolvidas, embora elas sejam importantes para a nossa pesquisa, interessa evidenciar como aspectos da criatividade no trabalho pedagógico se desenvolvem a partir de um Projeto de trabalho. Mitjáns Martínez (2014b), ao tratar do tema da criatividade no trabalho pedagógico, argumenta que o trabalho com projetos, incluindo projetos coletivos, geralmente favorece o desenvolvimento da criatividade. 
O projeto, que para as crianças foi muito envolvente porque abordava elementos da sua cultura, uma cultura infantil marcada por ícones televisivos internacionais e regida por desejos de consumo semelhantes aos de muitas crianças de qualquer parte do globo, acabou sendo envolvente também para a própria professora. Ela disse que o projeto havia sido marcante, obtendo o reconhecimento dos colegas e da gestão escolar e até alcançando visibilidade em todo o DF, uma vez que algumas das atividades desenvolvidas por ela com as crianças foram publicadas no livro Trabalho Coletivo das crianças da Educaşão Infantil do Distrito Federal: Eu-cidadão da plenarinha à participação (BRASIL, 2014), conforme Figura 5.

FIGURA 5 - Livro Plenarinha

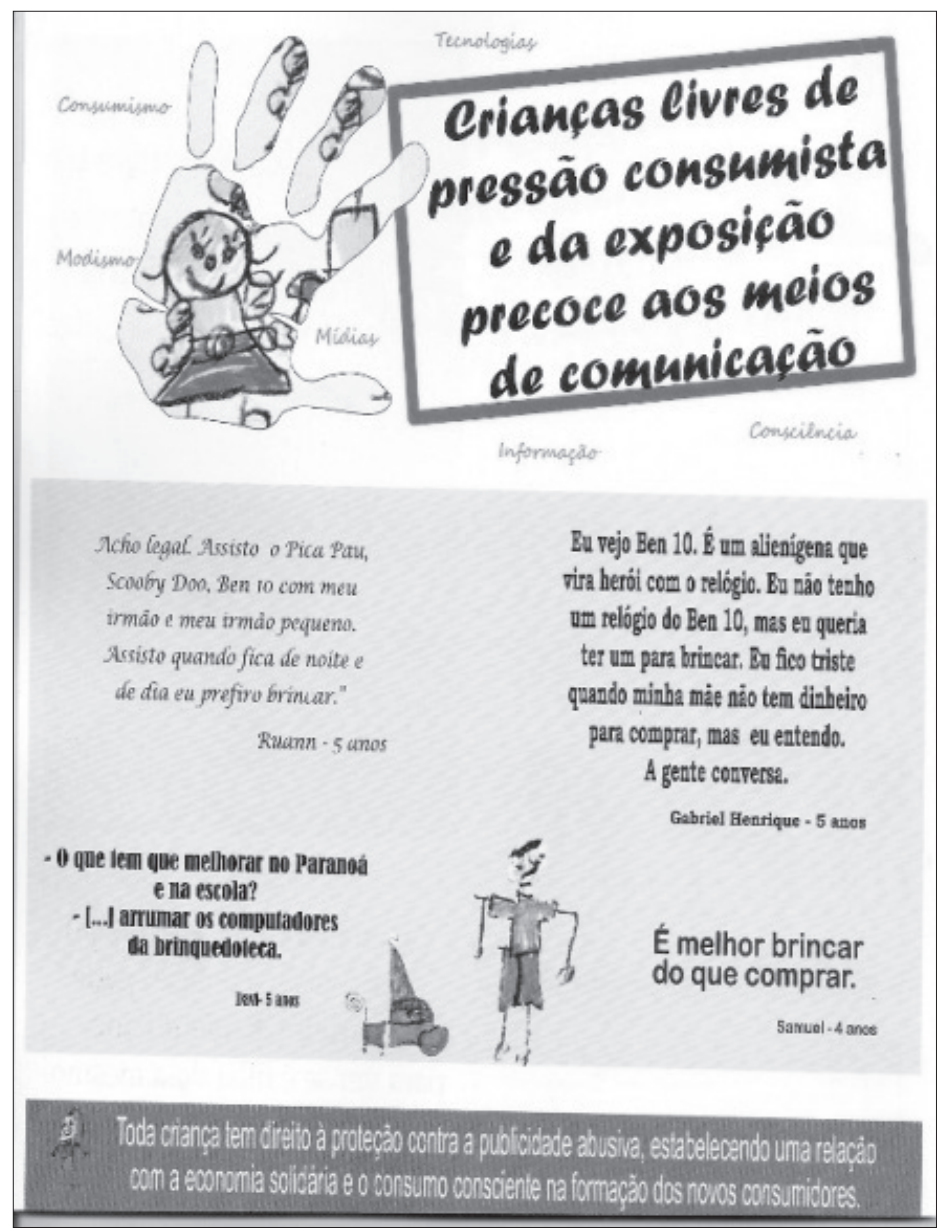

Fonte: BRASIL, 2014. 
Cabe, então, retomar o entendimento da criatividade na escola como o processo de produção de novidade com valor social para os indivíduos que participam deste contexto social (MITJÁNS MARTÍNEZ, 2009). No caso do projeto desenvolvido por essa professora, as estratégias utilizadas podem ser consideradas criativas no sentido de produção da novidade com valor social, uma vez que na escola era somente ela que estava desenvolvendo esse projeto, que acabou sendo novidade para o restante da escola. Era novidade também para as próprias crianças e suas famílias, na medida em que tratava de um tema bastante inusitado, diferente de outros temas que costumam se repeti, ano após ano, na Educação Infantil, como, por exemplo, o trabalho com as datas comemorativas. Foi novidade também para as crianças, uma vez que puderam vivenciar um processo que poderíamos denominar, de acordo com Kellner (2001), de alfabetização crítica da mídia, uma alfabetização pouco presente nos contextos escolares. Por meio dessa alfabetização, as crianças puderam pensar sobre o que provavelmente viam na televisão desde bebês sem qualquer tipo de questionamento. Em outras palavras, as crianças aprendem a ver televisão vendo, já que tal mídia se utiliza de um código visual que pode ser aprendido por crianças muito pequenas. Porém, pensar de modo crítico sobre o que veem requer um determinado tipo de alfabetização. Essa alfabetização, promovida pelo trabalho pedagógico criativo dessa professora, teve impacto em suas vidas, pelo menos na vida de algumas delas, e manifestou-se em mudanças em algumas de suas formas de agir e em determinados valores que se expressavam em pequenas práticas cotidianas do contexto escolar. Segundo entrevista com a professora, esse foi o caso de uma criança que, em uma situação conflituosa entre as meninas por causa de uma boneca pertencente ao universo midiático, a Polly, ao invés de participar do conflito/da disputa da boneca, disse: "Também é legal brincar com a boneca da escola. Vamos brincar de casinha?” (referindo-se a brincar de casinha com as bonecas da escola, que não tinham relação com a cultura da mídia). Sobre o fato de a realização desse projeto ter sido marcante para a professora, ela relatou que muitas experiências vividas durante esse trabalho haviam ficado em sua vida profissional. Por isso, ela percebia que, no ano de 2015, em algumas situações, ela retomou o tema e o trabalhou com as crianças, como a atividade realizada por ocasião do Dia das Mães. A professora propôs que as crianças criassem, inventassem algo que pudessem fazer/viver com as mães no Dia das Mães sem precisar usar dinheiro.

Também sobre formas criativas de lidar com a cultura da mídia e do consumo, outra professora criou um grupo de WhatsApp 
com as famílias de seus alunos durante o ano de 2015. O intuito da professora com a criação desse grupo foi, como declarado por ela em entrevista, aproximar o trabalho pedagógico entre famílias e professoras. A professora deixou claro que se surpreendeu quando percebeu que, dos 15 alunos, apenas uma mãe/pai não usava esse aplicativo como meio de comunicação. Inicialmente, o grupo era composto por 15 crianças, e o grupo virtual, por 14 famílias. No decorrer do ano letivo, ingressou mais um aluno na turma, e a família também entrou no grupo virtual, chamado $1^{\circ} \mathrm{B}$. A existência desse grupo virtual permitia que a professora solicitasse materiais que seriam utilizados nas práticas e projetos desenvolvidos com as crianças, realizasse informes sobre objetos esquecidos, comunicasse atividades festivas e passeios, entre outros assuntos que ela considerava pertinentes. Por outro lado, as famílias enviavam para a professora, e para os demais componentes do grupo, familiares das outras crianças, fotos e informações sobre a rotina ou acontecimentos na vida das crianças. Também costumavam justificar a ausência das crianças na escola e realizar perguntas sobre dúvidas que tinham em relação à escola, como se teria aula em um determinado dia ou não. As Figuras 7 e 8 são representativas das descrições por nós realizadas sobre os conteúdos postados no grupo virtual.

FIGURA 6 - Motivo de falta na escola

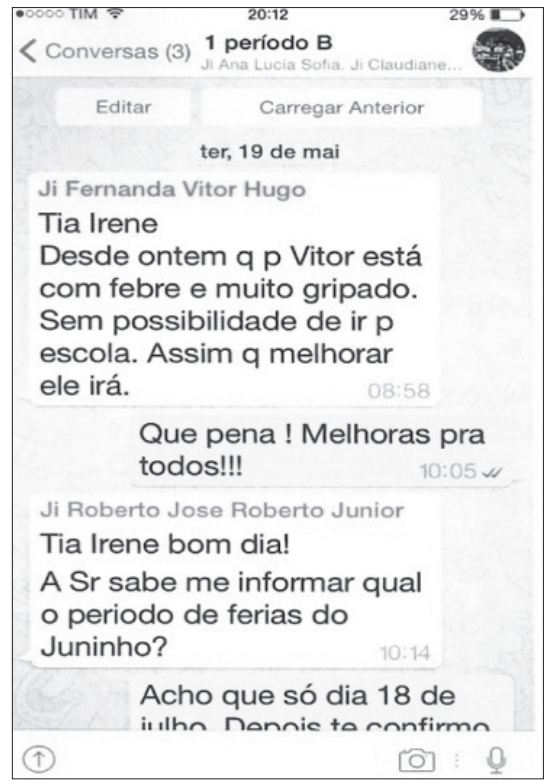

Fonte: Produção das autoras. 
FIGURA 7 - Dúvidas sobre objetos na escola

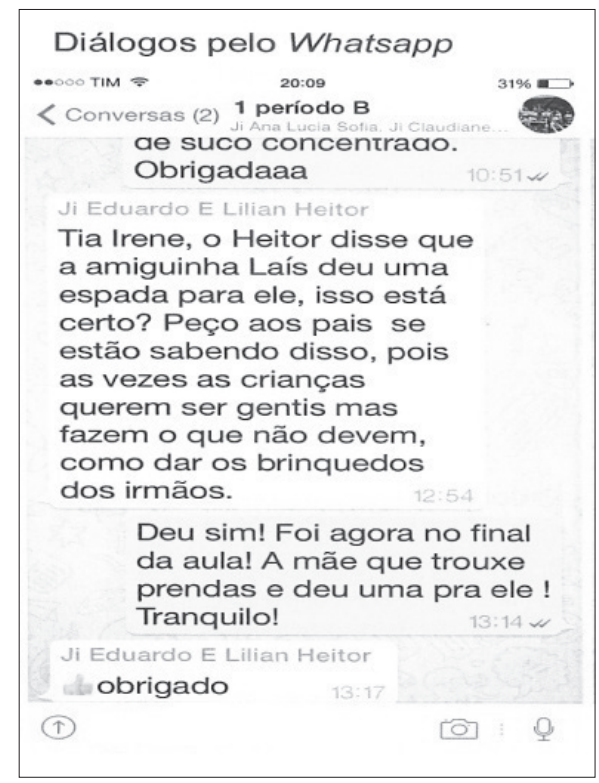

Fonte: Produção das autoras.

Podemos dizer que os modos de funcionamento desse grupo virtual estavam, em alguma medida, em consonância com muitos dos modos de funcionamento do mundo contemporâneo. Por exemplo, ao perguntarmos para a professora se poderíamos ver as agendas das crianças, ela respondeu que poderíamos, mas que ela usava mais o WhatsApp. Disse ainda que nas agendas é preciso colar os bilhetes e que às vezes não tem máquina copiadora funcionando na escola e é preciso ter tempo. Explicou que teve uma situação em que o diretor da escola disse que não seria possível aderir ao movimento de paralisação das atividades da categoria porque não haviam enviado bilhete nas agendas das crianças. Ela disse ter argumentado com ele que avisaria as famílias no mesmo instante pelo WhatsApp e que iria, sim, aderir à paralisação. Esse acontecimento remete-nos para $\mathrm{o}$ fato de que essa professora havia estabelecido, por meio do universo virtual, uma relação de instantaneidade e imediatez na comunicação com as famílias, em sintonia com as próprias características do mundo contemporâneo, descritas por Bauman (1999, 2001).

Essa instantaneidade também acontecia no momento da própria aula, quando a professora, em muitas circunstâncias, enviava fotografias do que estava acontecendo com as crianças, ou mesmo quando estava em casa e precisava se comunicar com as famílias: 
FIGURA 8 - Pintura da casa de bonecas

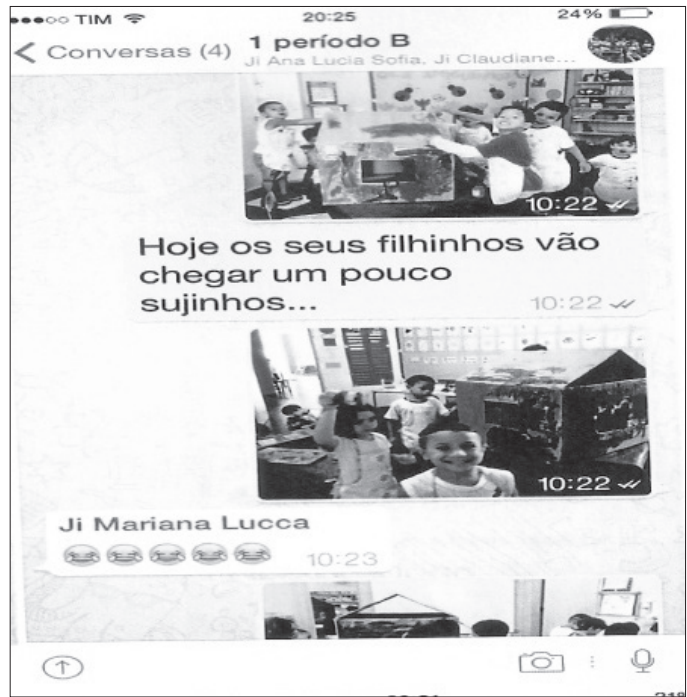

Fonte: Produção das autoras.

FIGURA 9 - Fiquem tranquilos que a Rosa, coordenadora, vai me substituir

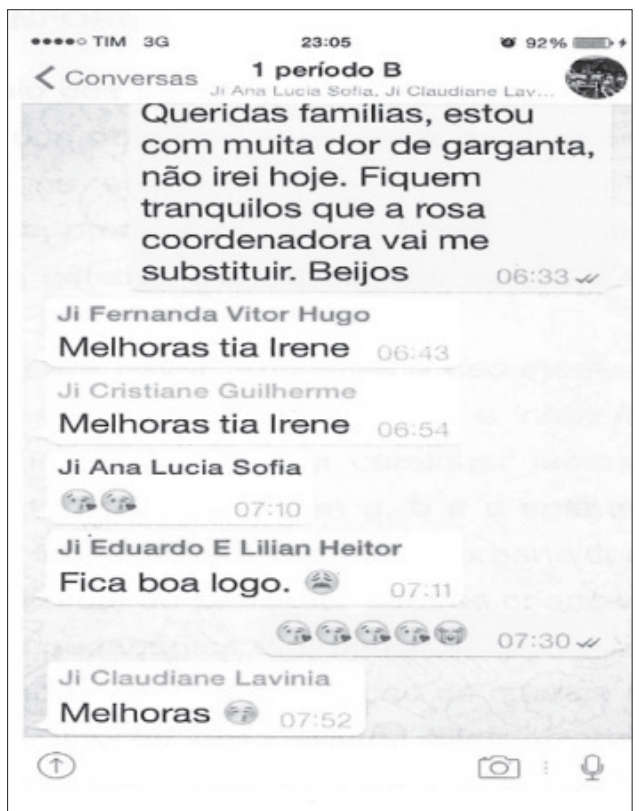

Fonte: Produção das autoras.

Dessas duas imagens do WhatsApp e das vivências que tivemos com o grupo e a professora, pode-se depreender que havia 
um investimento com elementos bastante criativos para que o clima relacional/emocional fosse o mais agradável e favorável a todos. Como se tratava de crianças com cinco anos de idade, as famílias se sentirem seguras em relação à escola é um dos elementos que podem gerar um clima emocional favorável, com implicações para a aprendizagem e para o desenvolvimento das crianças. Com essa ferramenta, tanto a professora compartilhava com as famílias o que acontecia na escola, quanto as famílias compartilhavam o que acontecia com as crianças quando não estavam na escola. Percebe-se, assim, a vida sendo compartilhada no universo virtual, em seus múltiplos aspectos, mas tendo como foco a própria escola e também a vida escolar. Mais do que isso, foi possível constatar que, com essa estratégia, a professora gerou novas formas de relacionamento com os pais (bem diferentes das tradicionais); conseguiu com eles proximidade afetiva, troca de informações e colaboração com o que estava sendo realizado com as crianças na escola (como a doação de baldinhos para o parque ou a presença de uma mãe em dia de passeio para ajudar com as crianças), entre outras possibilidades de relação. Eram possibilidades potencialmente favorecedoras de aprendizagem e desenvolvimento, tendo em conta que a articulação de ações família-escola, especialmente na infância, se constitui em elemento importante para a aprendizagem e para o desenvolvimento das crianças.

Sobre a vida escolar, houve, efetivamente, o envolvimento das famílias nos projetos desenvolvidos por essa professora durante o ano de 2015. Entre esses projetos, esteve o intitulado Alimentação Saudável, que tinha relação com o Projeto Político-Pedagógico da escola e estava atrelado também às inquietações da professora diante dos lanches industrializados que as crianças levavam para a escola. Nesse projeto, a cada semana, a professora escolhia um alimento que as crianças tinham dificuldade em comer (cebola, cenoura, beterraba), explorava-o em sala de aula, levando-o para as crianças (textura, gosto, cheiro, funções/vitaminas no organismo, etc.); depois, pedia que uma das famílias preparasse, junto com a criança, uma receita com esse alimento e enviasse para a escola para que todo o grupo degustasse. As experiências relacionadas a esse projeto, como negociar qual seria a família que ficaria responsável pela receita naquela semana, eram realizadas pelo WhatsApp. Os processos vividos relacionados a este e a outros projetos também eram compartilhados no universo virtual pela professora, pelas famílias e pelas próprias crianças, que gravavam mensagem de voz contando o que estava acontecendo ou mesmo emitindo opiniões sobre os projetos realizados. 
A experiência com o grupo do WhatsApp expressa a criatividade em importantes aspectos que fazem parte do Sistema Didático Integral proposto por Mitjáns Martínez (2014b, p. 72) e que acabam por configurar alguns elementos do trabalho pedagógico criativo. Um desses elementos diz respeito às "relações professor-aluno e [a]o clima comunicativo-emocional que caracteriza a sala de aula e a instituição escolar no seu conjunto". Essa experiência colaborou para estabelecer um clima comunicativo-emocional na sala de aula, na escola como um todo e com as famílias das crianças, favorável às próprias experiências de aprendizagem das crianças. Teve implicações, inclusive, nos processos comunicacionais sobre as atividades que eram realizadas na escola e nas que deveriam ser realizadas pelas crianças em casa, com a ajuda/participação das famílias.

\section{CONCLUIR, COMEÇAR OU CONTINUAR? O QUE FAZER DIANTE DA CULTURA DA MÍDIA E DO CONSUMO?}

As conclusões aqui apresentadas indicam a necessidade de começar ou dar continuidade a iniciativas do trabalho pedagógico criativo diante da cultura da mídia e do consumo. Além disso, apontam a urgência de investimentos financeiros, intelectuais e de efetivação de ações práticas diante da cultura da mídia e do consumo, não apenas por parte das professoras ou dos professores, mas das equipes pedagógicas das escolas, dos sistemas de ensino, das instituições que têm relação com a educação e dos próprios cursos - de formação inicial e continuada - de professores. Isso porque se trata de uma cultura inevitavelmente presente nos contextos escolares e na vida das crianças contemporâneas, pelo menos das que habitam os grandes centros urbanos. É preciso começar a lidar com essa cultura com intencionalidade pedagógica, tanto para promover aprendizagem e desenvolvimento nos indivíduos/crianças, quanto para contribuir com o tipo de pessoas e de sociedade que se quer formar, conforme demonstram iniciativas semelhantes de alguns países que já se preocupam em incluir em suas políticas a educação para a mídia e para o consumo.

Pelo que pudemos concluir a partir desta pesquisa, parece-nos que a criatividade se apresenta como uma importante e indispensável alternativa para se lidar com essa cultura dentro das escolas, em vez de apenas incorporá-la, reproduzi-la ou proibi-la. Retomamos aqui o entendimento de que a criatividade pode expressar-se em diferentes níveis (MITJÁNS MARTÍNEZ, 1997). Assim, ao invés de ocuparmo- 
nos em identificar ou discutir o nível de criatividade das estratégias, atitudes e atividades propostas pelas professoras, ocupamo-nos em descrever e interpretar alguns dos aspectos criativos - algo novo e com valor para a aprendizagem e o desenvolvimento das crianças e na vida cotidiana escolar - diante da cultura da mídia e do consumo. Isso não significa que, junto a este algo novo, também não estivesse algo "velho", como em algumas circunstâncias em que, em alguma medida, ocorria a incorporação e/ou reprodução da cultura da mídia e do consumo.

O que fazer, então, diante da cultura da mídia e do consumo? Essa é uma pergunta que nos serve muito mais para promover o pensar do que para ser respondida. Ao mesmo tempo, parece-nos que a criatividade no trabalho pedagógico pode compreender a própria condição de sujeito capaz de gerar alternativas que vão além dos sentidos hegemônicos postos em circulação pela cultura da mídia e do consumo. Parece-nos também que dois intensos temas, ainda tão ausentes do trabalho pedagógico, não se deixam mais calar no âmbito da educação escolarizada: a cultura da mídia e do consumo e a criatividade como expressão da subjetividade e, portanto, como alternativa dos sujeitos para lidar com essa cultura. Portanto, esses temas deveriam ser alvo de intensos debates na Educação Infantil e incorporados de modo veemente em documentos normativos que regem essa etapa da Educação, como é o caso das Diretrizes Curriculares Nacionais para a Educação Infantil (BRASIL, 2010), nas quais o tema do consumo, por exemplo, não está presente de modo explícito.

\section{REFERÊNCIAS}

BAUMAN, Z. Globalização: as consequências humanas. Tradução de Marcus Penchel. Rio de Janeiro: Jorge Zahar, 1999a.

BAUMAN, Z. Modernidade e ambivalência. Tradução de Marcus Penchel. Rio de Janeiro: Jorge Zahar, 1999b.

BAUMAN, Z. Modernidade líquida. Tradução de Plínio Dentzien. Rio de Janeiro: Jorge Zahar, 2001.

BAUMAN, Z. Vida para consumo. Tradução de Carlos Alberto Medeiros. Rio de Janeiro: Zahar, 2008.

BRASIL. Ministério da Educação. Secretaria de Educação Básica. Diretrizes curriculares nacionais para a educação infantil. Secretaria de Educação Básica. Brasília: MEC, SEB, 2010. BRASIL. Lei $\mathbf{n}^{\mathbf{0}} \mathbf{5 . 1 4 6}$, de 19 de agosto de 2013. Estabelece diretrizes para a promoção da alimentação saudável nas escolas da rede de ensino do Distrito Federal. Brasília: Câmara Legislativa do Distrito Federal, 2013.

BRASIL. Trabalho coletivo das crianças da educação infantil do Distrito Federal: Eu- 
cidadão da plenarinha à participação. Brasília: Secretaria de Estado de Educação do Distrito Federal/GDF, 2014.

CANCLINI, N. G. A globalização imaginada. Tradução de Sérgio Molina. São Paulo: Iluminuras, 2003

COSTA, M. V.; SILVEIRA, R. H. A revista Nova Escola e a constituição de identidades femininas. In: BRUSCHINI, C.; HOLLANDA, H. B. de (Org.). Horizontes Plurais: novos estudos de gênero no Brasil. São Paulo: Ed. 34, 1998. p. 343-378.

DEBORD, G. A sociedade do espetáculo. Tradução de Estela dos Santos Abreu. 7 ed. Rio de Janeiro: Contraponto, 1997.

GONZÁLEZ REY, F. L. Epistemología cualitativa y subjetividad. São Paulo: Education, 1997. GONZÁLEZ REY, F. L. Pesquisa Qualitativa em Psicologia: caminhos e desafios. São Paulo: Pioneira Thomson Learning, 2002.

GONZÁLEZ REY, F. L. Sujeito e Subjetividade: uma aproximação histórico-cultural. São Paulo: Pioneira Thomson Learning, 2004.

GONZÁlEZ REY, F. L. Pesquisa Qualitativa e Subjetividade: os processos de construção da informação. São Paulo: Langage Learning, 2011a.

GONZÁLEZ REY, F. L. Subjetividade e saúde: superando a clínica da patologia. São Paulo: Cortez, 2011b.

GONZÁLEZ REY, F. L. Sentidos subjetivos, lenguaje y sujeto: analizando uma perspectiva post racionalista em psicoterapia. Revista di Psichiatria, Itália, v. 46, p. 310-314, 2011c.

GONZÁLEZ REY, F. L. O Social na psicologia e a psicologia social: a emergência do sujeito. Tradução de Vera Lúcia Mello Joscelyne. 3. ed. Petrópolis-RJ: Vozes, 2012.

GONZÁLEZ REY, F. L. Ideias e Modelos Teóricos na Pesquisa Construtivo-Interpretativa. In: MARTÍNEZ, A. M.; NEUBERN, M.; MORI, V. D. (Org.) Subjetividade Contemporânea: discussões epistemológicas e metodológicas. Campinas-SP: Alínea, 2014. p. 13-34.

HALL, S. A identidade cultural na pós-modernidade. Tradução de Tomaz Tadeu da Silva e Guacira Lopes Louro. 9. ed. Rio de Janeiro: DP\&A, 2004.

HARVEY, D. Condição Pós-Moderna. Tradução de Adail Sobral e Maria Estela Gonçalves. São Paulo: Loyola, 1993.

JAMESON, F. Pós-Modernismo. A lógica cultural do capitalismo tardio. 2 ed. Tradução de Maria Elisa Cevasco. São Paulo: Ática, 2004.

KELLNER, D. Lendo imagens criticamente: em direção a uma pedagogia pós-moderna. In: SILVA, T. T. da (Org.). Alienígenas na sala de aula: uma introdução aos Estudos Culturais em Educação. Petrópolis: Vozes, 1995. p. 104-131.

KELLNER, D. A Cultura da Mídia. Tradução de Ivone Castilho Beneditti. São Paulo: EDUSC, 2001.

LIPOVETSKY, G. Metamorfoses da cultura: ética, mídia e empresa. Tradução de Juremir Machado da Silva. Porto Alegre: Sulina, 2004.

MITJÁNS MARTÍNEZ, A. Criatividade, Personalidade e Educação. Campinas: Papirus, 1997.

MITJÁNS MARTÍNEZ. O outro e sua significação para criatividade: implicações educacionais. In: SIMÃO, L. M.; MITJÁNS MARTÍNEZ, A. (Org.). O outro no 
desenvolvimento humano: diálogos para a pesquisa e a prática profissional em psicologia. São Paulo: Thomson, 2004. p. 77-99.

MITJÁNS MARTÍNEZ. A criatividade como princípio funcional da aula: limites e possibilidades. In: VEIGA, I. P. A. (Org.). Aula: Gênese, dimensões, princípios e práticas. Campinas: Papirus, 2008. p. 115-143.

MITJÁNS MARTÍNEZ. Vygotsky e a criatividade: novas leituras, novos desdobramentos. In: GIGLIO, Z. G.; WECHSLER, S. M.; BRAGOTTO, D. (Org.). Da inovação à criatividade. Campinas, Papirus, 2009. p. 11-38.

MITJÁNS MARTÍNEZ. O lugar da imaginação na aprendizagem escolar: suas implicações para o trabalho pedagógico. In: MARTÍNEZ, A. M.; ÁLVAREZ, P. (Org.) O sujeito que aprende: diálogo entre a psicanálise e o enfoque histórico-cultural. Brasília: Liber Livro, 2014a. p. 63-98.

MITJÁNS MARTÍNEZ. Criatividade no trabalho pedagógico e criatividade na aprendizagem: uma relação necessária? In: TACCA, M. C. V. R. (Org.). Aprendizagem e trabalho pedagógico. Campinas: Alínea, 2014b. p. 69-96.

MITJÁNS MARTÍNEZ. Um dos Desafios da Epistemologia Qualitativa: a criatividade do pesquisador. In: MARTÍNEZ, A. M.; NEUBERN, M.; MORI, V. D. (Org.) Subjetividade Contemporânea: discussões epistemológicas e metodológicas. Campinas, SP: Alínea, 2014c. p. 13-34.

MOREIRA, A. F. B.; CANDAU, V. M.. Indagações sobre currículo: currículo, conhecimento e cultura. In: BEAUCHAMP, J.; PAGEL, S. D.; NASCIMENTO, A. R. do (Org.). Indagações sobre currículo. Brasília: Ministério da Educação, Secretaria de Educação Básica, 2007. p. 12-23.

SCHOR, Juliet. Nascidos para comprar: uma leitura essencial para orientarmos nossas crianças na era do consumismo. Tradução de Eloisa Helena de Souza Cabral. São Paulo: Editora Gente, 2009.

STEINBERG, S.; KINCHELOE, J. L. (Org.). Cultura Infantil: a construção corporativa da infância. Rio de Janeiro: Civilização Brasileira, 2001.

VIGOTSKI, L. S. Imaginação e Criação na Infância: ensaio psicológico: livro para professores. Tradução de Zoia Prestes. São Paulo: Ática, 2009.

WILLIAMS, R. Cultura e Sociedade: 1780-1950. Tradução de Leônidas H.B. Hegenberg, Octanny Silveira da Mota e Anísio Teixeira. 3 ed. São Paulo: Companhia Editora Nacional, 1969.

\section{NOTAS}

${ }^{1}$ Esse critério é possível na medida em que existem pesquisas que estudam pessoas criativas e professores que realizam um trabalho pedagógico criativo.

${ }^{2}$ Lei $N^{\circ} 5.146$, de 19 de agosto de 2013, estabelece diretrizes para a promoção saudável nas escolas da rede de ensino do Distrito Federal.

${ }^{3}$ Cf. BRASIL, 2013.

${ }^{4} \mathrm{~A}$ Plenarinha caracteriza-se por atividades com várias instâncias de discussão - na escola, com as crianças e toda a comunidade escolar, na Regional de Ensino ou no Distrito Federal - sobre determinados temas. 
Submetido: 08/03/2016 Aprovado: 07/10/2016

Contato:

Mariangela Momo

Rua Marechal Mallet, casa número 2,

Bairro Tirol, Natal $|\mathrm{RN}|$ Brasil

CEP 59.015-150 